\title{
Medullary Thyroid Cancer with Normal Serum Calcitonin and Tubercular Neck Nodes: A Rare and Challenging Presentation
}

\author{
Suman Kharkwal ${ }^{1 \oplus}$, Anish Atchaya J², Rabishankar Singh ${ }^{3}$
}

\begin{abstract}
We report a highly unusual case of medullary carcinoma thyroid with normal serum calcitonin and tuberculous lymphadenitis mimicking metastatic neck nodes. A 26-year-old married woman was diagnosed with sporadic medullary carcinoma of thyroid on fine needle aspiration cytology (FNAC). Preoperative ultrasonography (USG) and contrast-enhanced computed tomography (CECT) neck suggested a metastasis in level IIB neck nodes. Patient underwent total thyroidectomy with central neck dissection with right modified neck dissection type III. Final histopathological report revealed medullary carcinoma thyroid (MTC) with tubercular lymphadenitis, none of 47 nodes retrieved had metastasis. She remains disease free after 2 years following surgery.

Keywords: Calcitonin, Medullary thyroid cancer, Total thyroidectomy.

World Journal of Endocrine Surgery (2021): 10.5005/jp-journals-10002-1401
\end{abstract}

\section{INTRODUCTION}

Medullary thyroid cancer accounts for $4 \%$ of all thyroid cancers ${ }^{1}$ and originates from the parafollicular C cells of thyroid. About $75 \%$ of MTC are sporadic and $15 \%$ being familial. Diagnosis and management are dependent on preoperative levels of serum calcitonin. ${ }^{2,3}$ Calcitonin is also a valuable tool for postsurgical surveillance, rising levels are indicative of recurrence. MTC with normal or undetectable levels of calcitonin is quite rare ${ }^{4-7}$ posing difficulty not only in preoperative setting but also for postoperative follow-up.

Lymph node metastases are present in $>70 \%$ of patients with palpable disease, and the risk of lymph node metastases is directly correlated with increasing levels of calcitonin..$^{8,9}$ Unlike other thyroid cancers such as papillary and follicular thyroid cancer, when medullary thyroid cancer spreads to lymph nodes, survival of patients is significantly affected. For this reason, guidelines for management of medullary thyroid cancer advocated for total thyroidectomy and central compartment lymph node removal as a minimum surgery for patients with medullary thyroid cancer ${ }^{3,8,9}$ and depending upon the imaging and clinical findings, lateral neck dissection is added.

We are reporting here a challenging case of a 26-year-old married woman diagnosed with sporadic medullary carcinoma of thyroid with normal preoperative serum calcitonin and tubercular lymphadenitis mimicking as nodal metastasis.

\section{Case Description}

A 26-year-female came to the surgical oncology OPD with the complaints of swelling in front of the neck for 7 months. There was no history of hoarseness of voice and difficulty in swallowing, pain over the swelling, or difficulty in breathing or orthopnea. There was no history of loss of weight, loss of appetite, irradiation, or surgical intervention. She had no symptoms or signs of hypo- or hyperthyroidism.

On examination, there was swelling in the right side of the thyroid region of $3 \times 2 \mathrm{~cm}$ which moved with deglutition, nontender, firm in consistency, and smooth surface. Level II lymph node of around
${ }^{1}$ Department of Surgical Oncology, ESI-PGIMSR, Delhi, India

${ }^{2,3}$ Department of Surgery, ESI-PGIMSR, Delhi, India

Corresponding Author: Suman Kharkwal, Department of Surgical Oncology, ESI PGIMSR, Delhi, India, e-mail: drsumankharkwal@ gmail.com

How to cite this article: Kharkwal S, Atchaya JA, Singh R. Medullary Thyroid Cancer with Normal Serum Calcitonin and Tubercular Neck Nodes: A Rare and Challenging Presentation. World J Endoc Surg 2021;13(2):61-63.

Source of support: Nil

Conflict of interest: None

$2 \times 1 \mathrm{~cm}$ was palpable in the right side. Thyroid function test was suggestive of euthyroid state. USG neck showed a heterogeneous hypoechoic lesion in the right side of the thyroid (Fig. 1A) and multiple enlarged level II lymph nodes (Fig. 1B). FNAC from thyroid nodule was diagnostic of medullary thyroid carcinoma (Fig. 2A). The patient's serum calcitonin was normal $5.9 \mathrm{pg} / \mathrm{mL}$ and $5.2 \mathrm{pg} / \mathrm{mL}$, measured twice from two different laboratories (reference range $5.0-11 \mathrm{pg} / \mathrm{mL}$ ). CEA was $17.1 \mathrm{ng} / \mathrm{mL}$ (reference range $<5.0 \mathrm{ng} / \mathrm{mL}$ ).

Serum calcium and intact parathyroid hormone (PTH) levels were normal.

Work-up for hyperparathyroidism and pheochromocytoma were negative. Patient was diagnosed as medullary thyroid carcinoma with right level II lymph node and was planned for total thyroidectomy with bilateral central neck dissection and right modified radical neck dissection. Intraoperatively, $2 \times 1 \mathrm{~cm}$ nodule in right lobe of thyroid was found along with small subcentimetric node in pretracheal area. Multiple nodes in right level II, III, IV largest $2 \times 1.5 \mathrm{~cm}$ level II. In the postoperative period, patient had hypocalcemic crisis and was managed with intravenous calcium and later shifted to oral calcium. She was discharged on postoperative day 14 on oral calcium. 2 months postsurgery, she was no longer on oral calcium and is being followed up every 3 monthly.

Her final histopathology report sprung a nice surprise for us. The primary tumor was $2 \times 1.5 \mathrm{~cm}$, no lymphovascular invasion was

(c) The Author(s). 2021 Open Access This article is distributed under the terms of the Creative Commons Attribution 4.0 International License (https://creativecommons. org/licenses/by-nc/4.0/), which permits unrestricted use, distribution, and non-commercial reproduction in any medium, provided you give appropriate credit to the original author(s) and the source, provide a link to the Creative Commons license, and indicate if changes were made. The Creative Commons Public Domain Dedication waiver (http://creativecommons.org/publicdomain/zero/1.0/) applies to the data made available in this article, unless otherwise stated. 


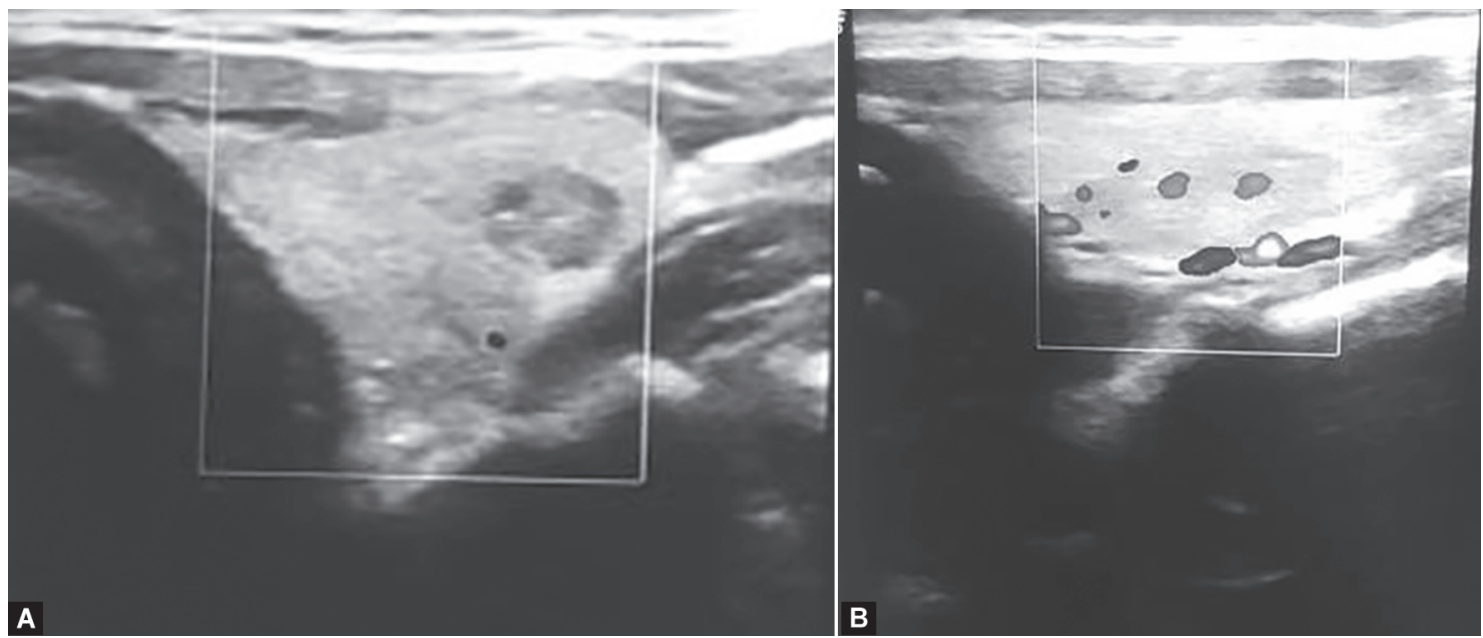

Figs $1 \mathrm{~A}$ and B: (A) Right Lobe showed oval heteroechoic lesion approximately $1.3 \times 2 \mathrm{~cm}$; (B) Right level II node
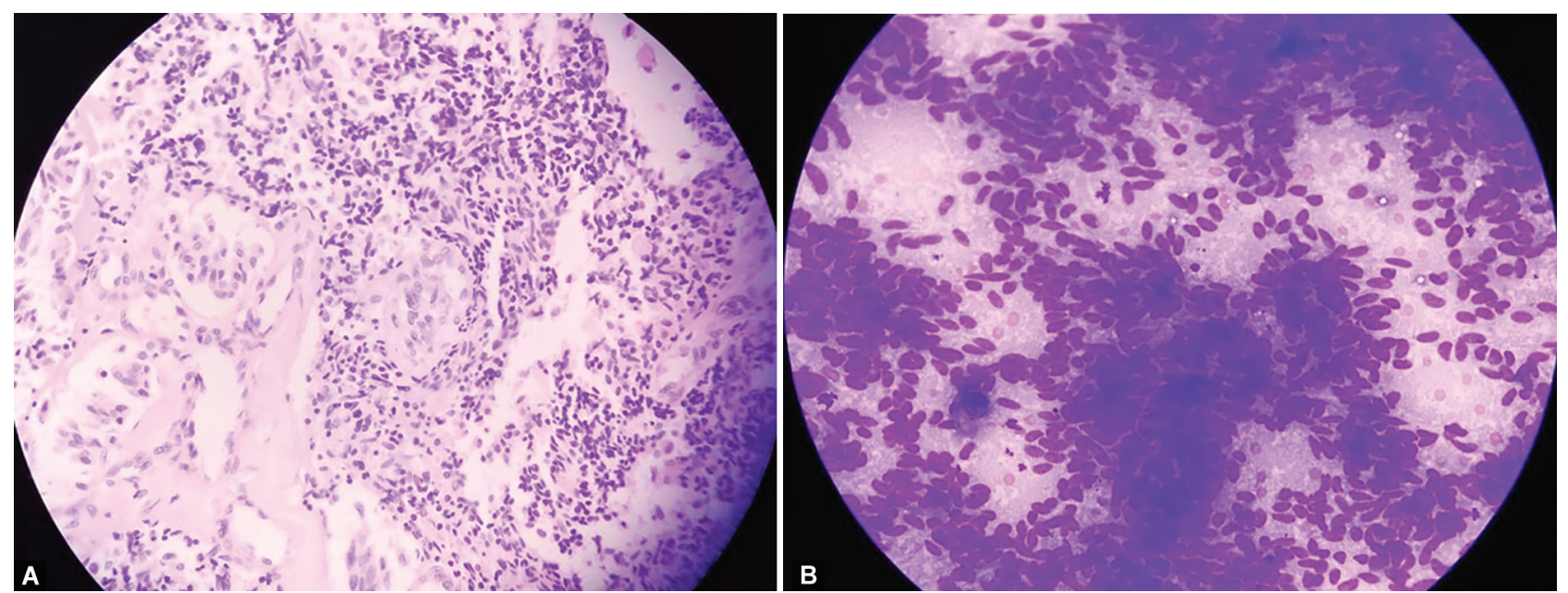

Figs 2A and B: (A) Low power view of hypercellular view of spindle cells (FNAC); (B) Low power view showing nests of predominantly round to spindle-shaped cells with finely stippled chromatin and inconspicuous nucleoli ( $40 \mathrm{x}, \mathrm{H}$ and $\mathrm{E}$ )

noted (Fig. 2B), rest of thyroid parenchyma, isthmus, and left lobe was normal. Out of 47 nodes in neck dissection specimen, none was positive for malignancy, all showed tubercular granuloma (Fig. 3). The patient was started on Thyroid replacement therapy and antitubercular drugs DOTS Category II. Heterozygous missense variation $\mathrm{p}$ V706 in exon 11 of RET gene was detected in mutation screening for RET gene.

Patient is symptom free and doing well 2 years postsurgery, her serum calcitonin and CEA continue to be in normal range.

\section{Discussion}

Medullary thyroid cancer with normal serum calcitonin is a rare and challenging entity causing difficulty not only during diagnosis but also in follow-up. In our case, not only the patient had normal serum Calcitonin level, she also had tubercular cervical lymphadenitis.

Serum Calcitonin is an important marker in the management of MTC not only for diagnosis but also forms an important component for follow-up. There are many theories as to why certain MTC do not have elevated calcitonin levels like production of aberrant calcitonin precursors not being recognized by standard tests, Hook effect, or Prozone effect (calcitonin assay interference) which is an immunologic phenomenon whereby the effectiveness of antibodies to form immune complexes is sometimes impaired when concentrations of an antibody or an antigen are very high. Ectopic thymic origin and dedifferentiation theory leading to loss of ability to secrete calcitonin $n^{5,6,7,10}$ but the exact cause still remains unclear.

Calcitonin-negative MTC poses a huge challenge in terms of follow-up. Many different modalities have been used by various authors such as Ultrasound neck, MRI, positron emission tomography - computed tomography (PET-CT). In our case, we followed the patient with USG neck, serum calcitonin, and CEA.

Cervical nodal metastasis is quite common in MTC and nodal involvement carries a poorer prognosis. ATA recommends that for patients of MTC, if preoperative imaging is positive in ipsilateral neck compartment but negative in the contralateral neck then patient should undergo total thyroidectomy with central lymph node dissection and dissection of involved lateral neck compartment, contralateral neck dissection to be considered, if serum calcitonin is $>200 \mathrm{pg} / \mathrm{mL}$. In our case, we did total thyroidectomy with central lymph node dissection and right side lateral nodal dissection. To our surprise, all the 47 nodes retrieved were negative for malignancy and positive for tuberculosis. Cases of thyroid malignancy with 


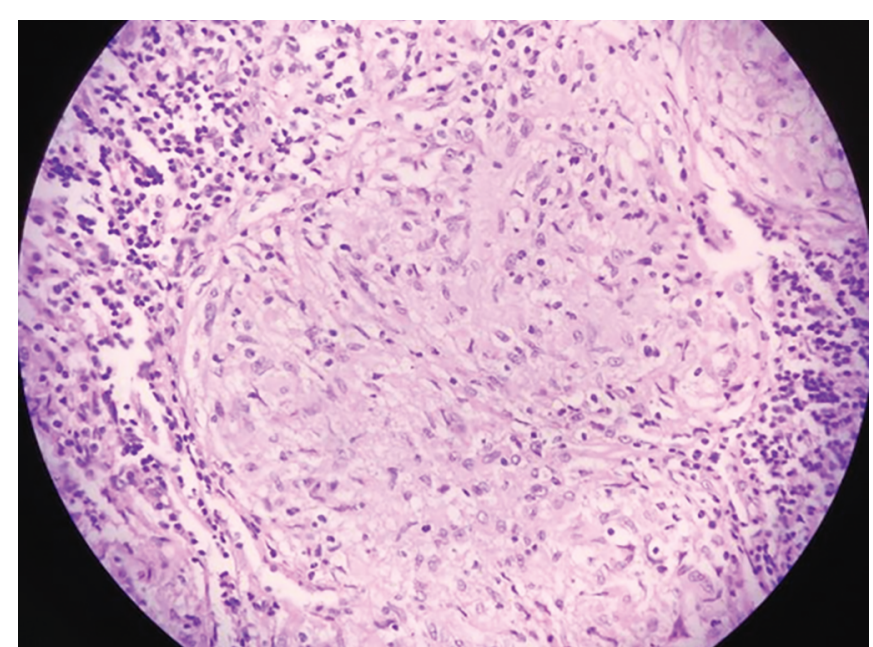

Fig. 3: Low power view of lymph node showing epithelioid cell granuloma

tubercular lymphadenitis of cervical nodes have been published earlier; ${ }^{11,12}$ however, almost all were with papillary thyroid cancer and none as unique as our case. The association of tubercular lymphadenopathy in our case also highlights the importance of keeping tuberculosis in mind while treating patients especially in endemic areas.

\section{Conclusion}

Calcitonin-negative MTC is a rare and challenging disease. Its pathophysiology is still not understood well and how to follow-up these patients also remains a significant concern. The coexistence of tuberculosis especially in endemic areas should always be kept in mind.

\section{OrCID}

Suman Kharkwal ๑ http://orcid.org/0000-0002-9027-5803

\section{References}

1. Fialkowski EA, Moley JF. Current approaches to medullary thyroid carcinoma, sporadic and familial. J Surg Oncol 2006;94:737-747. DOI: $10.1002 /$ jso. 20690

2. Jeffrey F. Moley, MD, St. Louis, Missouri. Medullary thyroid carcinoma: management of lymph node metastases. J Natl Compr Canc Netw 2010;8(5):549-556.

3. Wells SA, Asa SL, Dralle H, et al. Revised American Thyroid Association Guidelines for the Management of Medullary Thyroid Carcinoma The American Thyroid Association Guidelines Task Force on Medullary Thyroid Carcinoma. Thyroid 2015 Jun;25(6):567-610. DOI: 10.1089/thy.2014.0335

4. Wang TS, Ocal IT, Sosa JA, et al. Medullary thyroid carcinoma without marked elevation of calcitonin: a diagnostic and surveillance Dilemma. Thyroid. 2008;18(8):889-894. DOI: 10.1089/thy.2007.0413

5. Sand M, Gelos M, Sand D, et al. Serum calcitonin negative Medullary thyroid carcinoma. World J Surg Oncol 2006;4:97.

6. Brutsaert EF, Gersten AJ, Tassler AB, et al. Medullary thyroid cancer with undetectable serum calcitonin. J Clin Endocrinol Metab 2015; 100(2):337-341. DOI :10.1210/jc.2014-3095

7. Bockhorn M, Frilling $A$, Rewerk $S$, et al. Lack of elevated serum carcinoembryonic antigen and calcitonin in medullary thyroid carcinoma. Thyroid 2004;14:468-470.DOI: 10.1089/105072504323150813

8. Moley JF, DeBenedetti MK. Patterns of nodal metastases in palpable medullary thyroid carcinoma: recommendations for extent of node dissection. Ann Surg 1999;229:880-887; discussion 887-888. DOI: $10.1097 / 00000658-199906000-00016$

9. Machens A, Hinze R, Thomusch O, et al. Pattern of nodal metastasis for primary and reoperative thyroid cancer. World J Surg 2002;26:22-28. DOI: 10.1007/s00268-001-0176-3

10. Frank-Raue K, Machens A, Leidig-Bruckner G, et al. Prevalence and clinical spectrum of nonsecretory medullary thyroid carcinoma in a series of 839 patients with sporadic medullary thyroid carcinoma. Thyroid 2013;23:294-300. DOI: 10.1089/thy.2012.0236

11. Choi EC, Moon WJ, Lim YC. Tuberculous cervical lymphadenitis mimicking metastatic lymph nodes from papillary thyroid carcinoma. Br J Radiol 2009 ;82(982):e208-e211. DOI: 10.1259/bjr/91644902

12. Andrabi SAS, Bhat MH, Farhana B, et al. Tuberculous cervical lymphadenitis masquerding as metastasis from papillary thyroid carcinoma. Int J Endocrinol Metab 2012;10(3):569-572. DOI: $10.5812 /$ ijem.4500 